\title{
The prevalence of thyroid dysfunction in the antenatal population attending outpatient department in a tertiary health centre
}

\author{
Nair RV ${ }^{1}$, Manju $A^{2}$ \\ ${ }^{1}$ Dr Rema V. Nair, Professor, ${ }^{2}$ Dr Manju A, Senior Resident, both authors are attached with Department of Obstetrics \& \\ Gynaecology, Sree Mookambika Institute Of Medical Sciences, Padanilam,. Kulasekharam,. Kanya Kumari District,. Tamil \\ Nadu.- 629161, India
}

Address for Correspondence: Dr Prashnth V Solanke, Department of Community Medicine, Sree Mookambika Institute of Medical Sciences, Kulasekharam, Email: reemavnair1059@gmail.com

\begin{abstract}
Background: Normal function of thyroid gland will be affected during pregnancy because of its effect on pregnancy and its hormonal variations, other diseases of thyroid gland can also cause complications to both mother and fetus. Hypothyroidism is common in pregnancy-asymptomatic. Aims \& Objectives: To estimate the prevalence of thyroid dysfunction in the antenatal population attending out patient department in a tertiary health centre in Kulasekharam. Subjects and Methods: The study was conducted at Outpatient department of, Obstetrics \& Gynaecology in Sree Mookambika Institute of Medical Science, Kulasekharam. It is a cross sectional study where 60 antenatal women were included. The study involved administration of pretested questionnaire and measurement of thyroid function test. Results: About 58\% were diagnosed to have subclinical hypothyroidism and 10\% were diagnosed to have subclinical hyperthyroidism. Conclusion: Our study shows high prevalence of thyroid abnormalities in pregnant women suggest us the need for thyroid screening in pregnancy.
\end{abstract}

Key words: Thyroid function, Antenatal, $1^{\text {st }}$ trimester, Hypothyroidism, Hyperthyroidism

\section{Introduction}

The thyroid is an endocrine gland in the body, and consists of two connected lobes. It is found at the front of the neck, below the laryngeal prominence. It consists of right lobe, left lobe and isthmus, the isthmus connects the two lobes and crosses the anterior surface of $2^{\text {nd }}$ and $3^{\text {rd }}$ tracheal cartilage. It is in the visceral compartment of neck and its weight is about 30 grams. It was first described by Thomas Wharton in $1656[1,2]$.

Normal function of thyroid gland will be affected during pregnancy because of its effect on pregnancy and its hormonal variations, other diseases of thyroid gland can also cause complications to both mother and foetus [3]. Hypothyroidism is common in pregnancy-asymptomatic.

Women with subclinical hypothyroidism will be missed in early pregnancy and subclinical hyperthyroidism is usually symptomatic or the relapse of previous thyroid disorder. Pregnancy is a physiological state, associated with significant, but reversible changes in thyroid function. During the first trimester of pregnancy, the

Manuscript received: $12^{\text {th }}$ August 2016

Reviewed: $27^{\text {th }}$ August 2016

Author Corrected: $10^{\text {th }}$ September 2016

Accepted for Publication: $23^{\text {rd }}$ September 2016

Obsgyne Review: Journal of Obstetrics and Gynecology development of foetus is depending on mother, because thyroid function of foetus will start at 16 weeks of gestation. HCG stimulates thyroid gland because of its structural similarity to thyrotropin (Thyroid stimulating hormone) [4]. This leads to reduced serum thyrotropin levels during first trimester because of a negative feedback effect. Maternal hypothyroidism during first trimester (either subclinical or manifest) is known to cause impaired neuro psychomotor development and reduced mean intelligence quotient score in children [5]. Apart from these, spontaneous miscarriages, gestational hypertension, abruption placenta, foetal growth restriction and premature delivery are known to occur with maternal hypothyroidism [6]. Sahu, Meenakshi Titoria et al[3] showed that prevalence of thyroid dysfunction was high among antenatal population with subclinical hypothyroidism (6.47\%) and overt hypothyroidism (4.58\%). Similarly Casey BM et al[4] in USA showed that Pregnancies in women with subclinical hypothyroidism were 3 times more likely to be complicated by placental abruption. Leung AS et al Losangeles [5] conducted a study on 68 hypothyroid patients with no other medical illness were divided in to two groups according to thyroid function tests. The first one had 23 women with overt hypothyroidism and the second 45 women with Available online at : www.medresearch.in 8 | P a g e 
subclinical hypothyroidism. They sought to identify the pregnancy outcomes. Gestational hypertension - namely eclampsia, pre-eclampsia and pregnancy induced hypertension was significantly more in overt and subclinical hypothyroidism patients in the general population with rates of 22.15 and $7.6 \%$ respectively.

Thyroid disorders are among the common endocrine problems in pregnant women. It is now well established that not only overt, but subclinical thyroid dysfunction also has adverse effects on maternal and foetal outcome. There are few data from India about the prevalence of thyroid dysfunction in pregnancy.

\section{Aims and objectives}

To estimate the prevalence of thyroid dysfunction in the antenatal population attending outpatient department in a tertiary health centre in Kulasekharam

\section{Materials and Methods}

a) Study design: Cross sectional Study.

b) Study setting: Outpatient department of, Obstetrics \& Gynaecology, Sree Mookambika Institute Of Medical Science, Kulasekharam.

c) Approximate total duration of the study: One year.

d) Detailed description of the groups: Thyroid dysfunction in the antenatal population attending outpatient department in a tertiary health centre, Kulasekharam. First trimester: ( 8-10 weeks.)

e) Total sample size of the study: 60 cases.

f) Scientific basis of sample size used in the study: $\mathrm{P}=0.07 ; \quad \mathrm{E}=10 \%, \mathrm{q}=0.94 \mathbf{n}=\mathbf{4 p q} / \mathbf{E}^{2}=\mathbf{2 6}$, Minimum sample required was 26 , we took 60 antenatal cases

i) Sampling technique used in the study: Systematic Random Sampling

j) Inclusion criteria: All antenatal patients.

\section{Original Research Article}

k) Exclusion criteria: Pregnant women with known thyroid abnormalities. Pregnant women not willing to give consent

p) Parameters to be studied: Triiodothyronine (FT3), Thyroxine (FT4), Thyroid stimulating hormone (TSH).

q) Methods(s)/Technique(s)/Reagent(s)/Kit(s) etc. used to measure the qualitative parameters along with their manufacturing source details:

- Method for Thyroid Function test :Accu-Bind ELISA Microwells method

- Normal levels of Thyroid Function Test: (In pregnancy)

Free Triiodothyronine (FT3): $2.77-6.45 \mathrm{pmol} / \mathrm{L}$

Free Thyroxine(FT4): $9.80-28.9 \mathrm{pmol} / \mathrm{L}$

Thyroid Stimulating Hormone (TSH): $0.39-6.16$ $\mathrm{mIU} / \mathrm{L}$

r) Procedure in detail: After getting approval from Institutional Human Ethical Committee written informed consent was obtained from the patient before enrolling them into study.

A detailed relevant history and signs and symptoms of thyroid disorders were recorded. A thorough general physical examination with reference to pulse, blood pressure, Temperature, respiratory rate were noted followed by Cardio vascular system, Central nervous system, Respiratory system, Local examination of thyroid.

Fasting morning blood sample for fasting thyroid function was collected by venipuncture $(0.2 \mathrm{ml})$ without anticoagulants in each trimester. Patients were advised to attend gynaecology outpatient department for further management.

The study Parameters entered in Microsoft Excel spread sheet and statistically analysed using program $\mathrm{R}$, Version 3.00

\section{Results}

The prevalence of thyroid dysfunction among ante natal women was $68 \%$, of these $58 \%$ were diagnosed to have subclinical hypothyroidism, $10 \%$ had subclinical hyperthyroidism (Table 1). It was more in the $26-30$ years of age group (43.3\%). With reference obstetric score, maximum number of antenatal women with thyroid function test variation were primigravida about $43.3 \%$, multigravida with living accounts of $36.7 \%$, multigravida with abortion were $6.7 \%$ and multigravida with living $\&$ abortion were $13.3 \%$.

Among the 60 antenatal women $65 \%$ were with no complaints; $26.7 \%$ presented with lower abdominal pain; $5 \%$ had lower abdominal pain \& spotting per vaginum; $3.3 \%$ were with only spotting per vaginum.

In this study only $5 \%$ of antenatal women were using non-iodized salt and other $95 \%$ were using iodized salt in their diet. $15 \%$ of antenatal women had family history of thyroid disease. In our study $66.7 \%$ of antenatal women had abnormal general 
examination findings. About $60 \%$ of the antenatal women had pre pregnancy weight between $50-60 \mathrm{~kg}$; $16.7 \%$ were less than $50 \mathrm{~kg} ; 13.3 \%$ were $60-70 \mathrm{~kg}$ and only $10 \%$ were more than $70 \mathrm{~kg}$. The pre pregnancy BMI in $58.3 \%$ was normal; $30 \%$ were overweight; $6.7 \%$ were underweight and $5 \%$ were obese.

Thyroid gland examination was normal in about $83.3 \%$. In about $98.3 \% \mathrm{fT}_{3}$ was $2.77-6.45 \mathrm{pmo} 1 / \mathrm{L} ; 1.7 \% \mathrm{had}<2.77 \mathrm{pmol} / \mathrm{L}$. Free $\mathrm{T}_{4}$ value was abnormal in only $3.3 \%$ of the antenatal women

Table-1: TSH level among Antenatal women.

\begin{tabular}{|c|c|c|}
\hline TSH & Frequency & Percent \\
\hline$<0.39$ & 6 & 10.0 \\
\hline $0.39-6.16$ & 19 & 31.66 \\
\hline$>6.16$ & 35 & 58.33 \\
\hline Total & $\mathbf{6 0}$ & $\mathbf{1 0 0 . 0}$ \\
\hline
\end{tabular}

\section{Discussion}

The present study was carried out among 60 antenatal women who were screened for thyroid disorders. The prevalence of subclinical hypothyroidism in our study is $35(58 \%)$, subclinical hyperthyroidism is $6(10 \%)$ similar findings were found in a study done by Leung AS et al[5] in which prevalence of subclinical hypothyroidism was $55 \%$.

The occurrence of subclinical hypothyroidism in our study is $58 \%$ which is not consistent with a study done by Sahu MT et al [3]; in which the prevalence was $0.9 \%$. The prevalence of subclinical hyperthyroidism in the current study $(10 \%)$ is comparable with other studies done by Tuijamannisto et al [7] (3.5\%) and Stagnaro-Green A study [8] (0.5\%).

Liesenkotter et al[9], in their study proved that iodine supplementation during pregnancy in an area with moderate / severe iodine deficiency helps in prevention of early endemic goitre and increase in thyroid gland volume. Hence concluded that iodine supplementation can have long lasting beneficial effect on pregnancy.

In our study, $5 \%$ of antenatal women were using noniodized salt. In our study 24 antenatal woman were with thyroid function test abnormalities among these 10 women were asymptomatic and without any antenatal complications, 11 antenatal women had lower abdominal pain \& spotting per vagina and one had spotting per vagina. In this study, only 4 antenatal women had history of previous pregnancy loss. In a study done by Robert Negro et al[10], the hyperthyroidism in low risk group was associated with complications like abortion (14.3\%) also found that high maternal TSH level was associated with an increased risk of pregnancy loss because TSH is inversely related to hCG levels.

\section{Conclusion}

Our study shows high prevalence of thyroid abnormalities in pregnant women suggest us the need for thyroid screening in pregnancy, in our study 35 were diagnosed to have subclinical hypothyroidism and 6 had subclinical hyperthyroidism. So routine screening for thyroid dysfunction is recommended in pregnancy, along with a close endocrine follow-up in order to obtain good pregnancy outcome

Funding: Nil, Conflict of interest: Nil Permission from IRB: Yes

\section{References}

1. Richard L. Draka, Wagne Vog1, Adam W.M. Mitchell “Gray's Anatomy for Students" : 915-18 : 2005.

2. Garel C, Léger J. Thyroid imaging in children. Endocr Dev. 2007;10:43-61.

3. Sahu MT, Das V, Mittal S, Agarwal A, Sahu M. Overt and subclinical thyroid dysfunction among Indian pregnant women and its effect on maternal and fetal outcome. Arch Gynecol Obstet. 2010 Feb;281(2):215-20. doi: 10.1007/s00404-009-1105-1. Epub 2009 May 13.

4. Casey BM, Dashe JS, Wells CE, McIntire DD, Byrd W, Leveno KJ, Cunningham FG. Subclinical hypothyroidism and pregnancy outcomes. Obstet Gynecol. 2005 Feb;105 (2):239-45.

5. Leung AS, Millar LK, Koonings PP, Montoro M, Mestman JH. Perinatal outcome in hypothyroid pregnancies. Obstet Gynecol. 1993 Mar;81(3):349-53.

6. Vaidya B, Anthony S, Bilous M, Shields B, Drury J, Hutchison S, Bilous R. Detection of thyroid dysfunction 
in early pregnancy: Universal screening or targeted highrisk case finding? J Clin Endocrinol Metab. 2007 Jan; 92 (1):203-7. Epub 2006 Oct 10.

7. Männistö T, Vääräsmäki M, Pouta $A$, Hartikainen $A L$, Ruokonen A, Surcel HM, Bloigu A, Järvelin MR, Suvanto E. Thyroid dysfunction and autoantibodies during pregnancy as predictive factors of pregnancy complications and maternal morbidity in later life. J Clin Endocrinol Metab. 2010 Mar;95(3):1084-94. doi: 10. 1210/jc. 2009-1904. Epub 2010 Jan 15.

8. Stangaro GA et al. Overt Hyperthyroidism and Hypothyroidism during pregnancy. Clin Obstet Gynaecol 2011; 54(3):478-82.
9. Millar LK, Wing DA, Leung AS, Koonings PP, Montoro MN, Mestman JH. Low birth weight and preeclampsia in pregnancies complicated by hyperthyroidism. Obstet Gynecol. 1994 Dec;84(6): 946-9.

10. Negro R, Schwartz A, Gismondi R, Tinelli A, Mangieri T, Stagnaro-Green A. Universal screening versus case finding for detection and treatment of thyroid hormonal dysfunction during pregnancy. J Clin Endocrinol Metab. 2010 Apr;95(4):1699-707. doi: 10. 1210/jc. 2009-2009. Epub 2010 Feb 3.

\section{How to cite this article?}

Nair RV, Manju A. The prevalence of thyroid dysfunction in the antenatal population attending outpatient department in a tertiary health centre. Obs Rev: J obstet Gynecol 2016;2(2):8-11. doi: 10.17511/joog.2016.i02.03. 